\title{
Antitussive activity of alcoxyphenyl carbamic acid analogues
}

\author{
Jana Jurecekova ${ }^{1}$, Gabriela Nosalova ${ }^{1,2}$, Ludovit Jurecek ${ }^{1}$, Jozef Csollei ${ }^{3}$, Veronika Sivova ${ }^{1}$ \\ and Slavomir Nosal ${ }^{4}$ \\ ${ }^{1}$ Biomedical Center Martin, Jessenius Faculty of Medicine, Comenius University in Bratislava, Malá Hora 4D, Martin, \\ Slovakia \\ ${ }^{2}$ Department of Pharmacology, Jessenius Faculty of Medicine, Comenius University in Bratislava, Malá Hora 4D, Martin, \\ Slovakia \\ ${ }^{3}$ Department of Chemical Drugs, Faculty of Pharmacy, University of Veterinary and Pharmaceutical Sciences, Palackeho \\ 1/3, Brno, Czech Republic \\ ${ }^{4}$ Department of Pediatric Anesthesiology and Intensive Medicine, Jessenius Faculty of Medicine, Comenius University in \\ Bratislava, Kollarova 2, Martin, Slovakia
}

\begin{abstract}
In this study we report pharmacological evaluation of four newly synthetized analogues of alcoxyphenyl carbamic acid, structurally related to butamirate citrate that is frequently used as cough suppressing drug, and marked as ATK 231, ATK 241, ATK 251 and ATK 261. These agents with various modifications of the molecular structure have been tested for antitussive activity in cough induced by inhalation of aerosol of citric acid $(0.3 \mathrm{M})$ over 3 minutes using conscious guinea pigs. Results revealed significant cough suppressing activity without significant influence on specific airways resistances in all tested substances. ATK 231 and ATK241 showed significantly higher total antitussive activities when compared to both codeine phosphate and butamirate citrate, while ATK 251 only comparing to butamirate citrate. We did not observe any notable adverse effects and these compounds could thus potentially represent promising new non-narcotic antitussives suitable for further studies.
\end{abstract}

Key words: Cough — Citric acid - Guinea pigs - Airways resistance — Antitussive activity

\section{Introduction}

The therapy of pathological cough reflex still remains one of the major unmet medical needs (Dicpinigaitis 2011). Currently, the availability of prescription or over-thecounter medications does not definitely satisfy the need of clinical practice, although high proportion of patients seeks the health care due to acute or chronic cough. Some effective centrally acting drugs came with serious side effects, while effectiveness of many peripherally acting medications has not been fully confirmed (Young and Smith 2011; Derebery and Dicpinigaiti 2013). Butamirate citrate is currently widely used in clinical practice in adults

Correspondence to: Slavomir Nosal, Comenius University in Bratislava, Jessenius Faculty of Medicine, Department of Pediatric Anesthesiology and Intensive Medicine, Kollarova 2, 03601 Martin, Slovakia

E-mail: snosal@jfmed.uniba.sk as well as in children for its cough modulation properties (Schenker 1983; Miko 2005; Molassiotis et al. 2010; Jurica 2013). Cough suppressive activity of butamirate citrate in animal models was described already in animal models several decades ago (Nosal'ova and Strapkova 1986; Szuk et al. 1987). Since then, only a limited number of manuscripts has dealt with this potent cough modulating agent and neither described exact mechanism of its action in details. Generally accepted are its local anesthetic, anti-inflammatory and spasmolytic properties contributing to its peripheral cough suppressive activity (Eddy et al. 1969; Calderon et al. 1994; Brown et al. 2004). Some studies found that butamirate binds to the dextromethorphan binding site of sigma receptors and NMDA receptors in guinea pig brain with the high affinity and thus possibly exerting some central antitussive properties (Klein and Musacchio 1989). Butamirate as a 2-(2-diethylaminoethoxy)-ethyl ester is chemically related to oxeladine and pentoxyverine. Pentoxyverine has also been described to act as an agonist 
on sigma receptors and antagonist on muscarinic receptors (Brown et al. 2004).

We identified four different newly synthetized compounds - alkaline esters of alcoxyphenylcarbamic acid with citric acid, marked as ATK 231, ATK 241, ATK 251 and ATK 261. We assessed antitussive properties and specific airway resistance influence comparing to codeine phosphate, a reference antitussive agent, as positive control 1, to butamirate citrate, chemically related to studied compounds, as positive control 2 and water for injection as negative control in chemically induced cough using experimental guinea pigs.

\section{Materials and Methods}

\section{Tested material}

Four different compounds - analogues of alcoxyphenylcarbamic acid chemically related to butamirate citrate, marked as ATK 231, ATK 241, ATK 251 and ATK 261, were selectively synthetized in order to evaluate the cough suppressing properties of new synthetic non-narcotic antitussives. All of them structurally belong to carbamate type phenylacetic acid esters (Table 1). This group was established in the study of structure and biological activity of antispasmodic adiphenine. Butamirate citrate and pentoxyverine, structurally belonging to this group, are used in clinical practice currently.

\section{Synthesis of analogues of alcoxyphenyl carbamic acid}

The scheme of the synthesis of tested compounds ATK 231, ATK 241, ATK 251 and ATK 261 is shown in Scheme 1.

\section{Synthesis of 2-(2-diethylaminoethoxy)-ethanol}

The compound was obtained by heating the reaction mixture of diethylamine and ethylene oxide in autoclave to $120^{\circ} \mathrm{C}$ for $5 \mathrm{~h}$. The residue was distilled under reduced pressure, yielding the fraction boiling at $150-156^{\circ} \mathrm{C}$ (Carissimi et al. 1965).

Table 1. Chemical structure, formulas, molecular weights of tested analogues of alcoxyphenyl carbamic acid

\begin{tabular}{llll}
\hline Sample & $\mathrm{R}$ & Summary formula & $\mathrm{MW}$ \\
\hline ATK 231 & $\mathrm{C}_{3} \mathrm{H}_{7}$ & $\mathrm{C}_{24} \mathrm{H}_{38} \mathrm{~N}_{2} \mathrm{O}_{11}$ & 530.54 \\
ATK 241 & $\mathrm{C}_{4} \mathrm{H}_{9}$ & $\mathrm{C}_{25} \mathrm{H}_{40} \mathrm{~N}_{2} \mathrm{O}_{11}$ & 544.57 \\
ATK 251 & $\mathrm{C}_{5} \mathrm{H}_{11}$ & $\mathrm{C}_{26} \mathrm{H}_{42} \mathrm{~N}_{2} \mathrm{O}_{11}$ & 558.60 \\
ATK 261 & $\mathrm{C}_{6} \mathrm{H}_{13}$ & $\mathrm{C}_{27} \mathrm{H}_{44} \mathrm{~N}_{2} \mathrm{O}_{11}$ & 572.62 \\
\hline
\end{tabular}<smiles>CCNC(C)C1CO1</smiles><smiles>CCN(CC)CCOCCOC(=O)Nc1ccccc1O</smiles>

Scheme 1. Scheme of synthesis of tested analogues of alcoxyphenyl carbamic acid.

\section{Synthesis of substituted phenylisocyanates}

The compounds were prepared by reaction of substituted anilines with a toluene solution of phosgene.

General procedures for the synthesis of carbamates and their salts

A mixture of freshly distilled alkoxyphenylisocyanate $(0.03 \mathrm{M})$, diethylaminoethoxyethanole $(0.03 \mathrm{M})$ and $15 \mathrm{ml}$ of anhydrous toluene was heated for $10 \mathrm{~h}$ under reflux. After cooling, the toluene solution was extracted with water and organic layers were dried over anhydrous sodium sulfate. The solvent was removed by distillation under reduced pressure. The compounds were then converted into their citrates and recrystallized.

\section{Methods of assessment of chemically induced cough reflex and specific airways resistance}

\section{Animals}

The antitussive activity observed as a number of cough efforts and specific airways resistance in vivo has been tested in guinea pigs. Adult male guinea pigs, weighing 200-350 g, supplied by Department of Experimental Pharmacology (Slovak Academy of Science, Dobra Voda, Slovakia) were kept in the animal house with food and water ad libitum with standard air-conditioning system. Animals were kept in quarantine at least one week before starting the experiment. Each substance as well as control agents ("positive" codeine and buramirate and "negative" vehicle) were tested on separate group of 10 guinea pigs.

The experimental protocols have been approved by the Institutional Ethics Committee of Jessenius Faculty of Medicine, Comenius University in Martin (permission number IRB 00005636) and complied with Slovakian and European 
Community regulations for the use of laboratory animals. This is in accordance with the revised Declaration of Helsinki from 1983 and follows the criteria of experimental animal well fare.

\section{The assessment of chemically induced cough and specific airways resistance}

Conscious guinea pigs were placed in a double-chamber bodyplethysmograph box (HSE type 855, Hugo Sachs Elektronik, Germany) and restricted so that the head of the animal protruded into nasal chamber and the neck was sealed with a soft diaphragm. The cough reflex was induced by inhalation of citric acid aerosol (concentration $0.3 \mathrm{M}$ ) generated by a jet nebulizer (PARI jet nebulizer, Paul Ritzau, Pari-Werk GmBH, Germany, output 51/s, particle mass median diameter $1.2 \mu \mathrm{m})$. The aerosol was delivered into the head chamber of the bodyplethysmograph for 3 min. Cough efforts, defined as sudden enhancements of expiratory air flow associated with typical motion and sound observed by trained personnel were registered over this time interval. The airway smooth muscle reactivity in vivo was expressed as the specific airway resistance calculated according to Pennock et al. (1979) by the time difference between the pressure changes in both parts of bodyplethysmograph during normal breathing pattern. Cough efforts as well as specific airway resistances were firstly induced by citric acid and registered in every animal before administration of an agent. Subsequently, tested substance was applied orally. All tested substances (marked as ATK 231, ATK 241, ATK 251 and ATK 261) were applied orally in the doses $50 \mathrm{mg} / \mathrm{kg}$ of body weight. Similarly, vehicle ("negative control" - water for injection) was given orally in the dose $1 \mathrm{ml} / \mathrm{kg}$ of body weight, codeine phosphate ("positive control 1") in the dose $10 \mathrm{mg} / \mathrm{kg}$ of body weight and butamirate citrate ("positive control 2") in the dose $50 \mathrm{mg} / \mathrm{kg}$ of body weight. The cough reflex was induced again by inhalation of citric acid aerosol in defined time intervals of 30, 60, 120 and 300 min after administration of the compounds. A minimum 2-h interval between two measurements was set to prevent adaptation of cough receptors as well as general adaptation of guinea pigs to this kind of irritation. Therefore, the experiment with individual animal to test the activity of selected compound was divided into two days when different time intervals were measured. In the first day, cough efforts in intervals of 60 and $300 \mathrm{~min}$ were detected. The next day the same animal was used for the experiment with the same compound but measurement was done firstly in 30-min interval and after 2-h interruption, the substance was given again to the animal. The cough efforts were registered then after $120 \mathrm{~min}$. The maximum duration of the experiment was approximately $6 \mathrm{~h}$ per day.

\section{Statistical analysis}

Paired one-tailed $t$-test was used for the statistical analysis of the differences between the numbers of cough efforts recorded before administration of individual substances and after defined time intervals post administration of individual substances. All data are represented as mean \pm standard errors of the mean ( \pm S.E.M.) and $p<0.05$ was considered as threshold for statistical significance. The total antitussive activity of individual compounds is represented by average percentage of decrease in the number of cough efforts. Paired one-tailed $t$-test was used also for the statistical analysis of the differences between the total antitussive activities of compounds.

\section{Results}

Four different samples (ATK 231, ATK 241, ATK 251 and ATK 261) synthetized as potential novel synthetic non-narcotic antitussives were tested for cough suppressing activity and their impact on specific airway resistance.

Oral administration of ATK 231 and ATK 241 in the dose $50 \mathrm{mg} / \mathrm{kg}$ of body weight resulted in dramatic and statistically significant reduction of cough efforts already after $30 \mathrm{~min}$ ( $p=0.005$ for ATK 231 and $p=0.0004$ for ATK 241). This cough-suppressive effect persisted over all remaining time intervals $(60,120$ and $300 \mathrm{~min})$ until the end of experiment (Fig. 1).

ATK 251 administered orally in the dose $50 \mathrm{mg} / \mathrm{kg}$ of body weight led to less pronounced, but still statistically significant suppression of cough efforts after $30 \mathrm{~min}$ ( $p=$ 0.003). Maximal antitussive effect was reached $60 \mathrm{~min}$ after administration $(p=0.0003)$ and remained statistically significant until end of observation period at $300 \mathrm{~min}(p=$ 0.0007) (Fig. 1).

Similarly, oral administration of ATK 261 in dose $50 \mathrm{mg} /$ $\mathrm{kg}$ of body weight led to significant reduction of cough efforts already after 30 min $(p=0.007)$. Maximal cough suppression was achieved 120 minutes after oral administration $(p=$ 0.003 ) and remained statistically significant until the end of observation period at $300 \mathrm{~min}(p=0.006)$ (Fig. 1).

Fig. 2 gives an overview of total antitussive activities, expressed as an average decrease in number of cough efforts during the whole duration of experiment, in all different synthetic alkaline esters of alcoxyphenyl carbamic acid comparing to reference antitussive drug codeine phosphate and chemically related antitussive butamirate citrate. Generally, the strongest cough suppression was observed after administration of ATK 231 (86.6\%) and ATK 241 (86.3\%). ATK 261 suppressed the cough efforts by $71.6 \%$ and the least antitussive potency was found in ATK 251 (67.6\%). There were no significant differences in total antitussive activities 


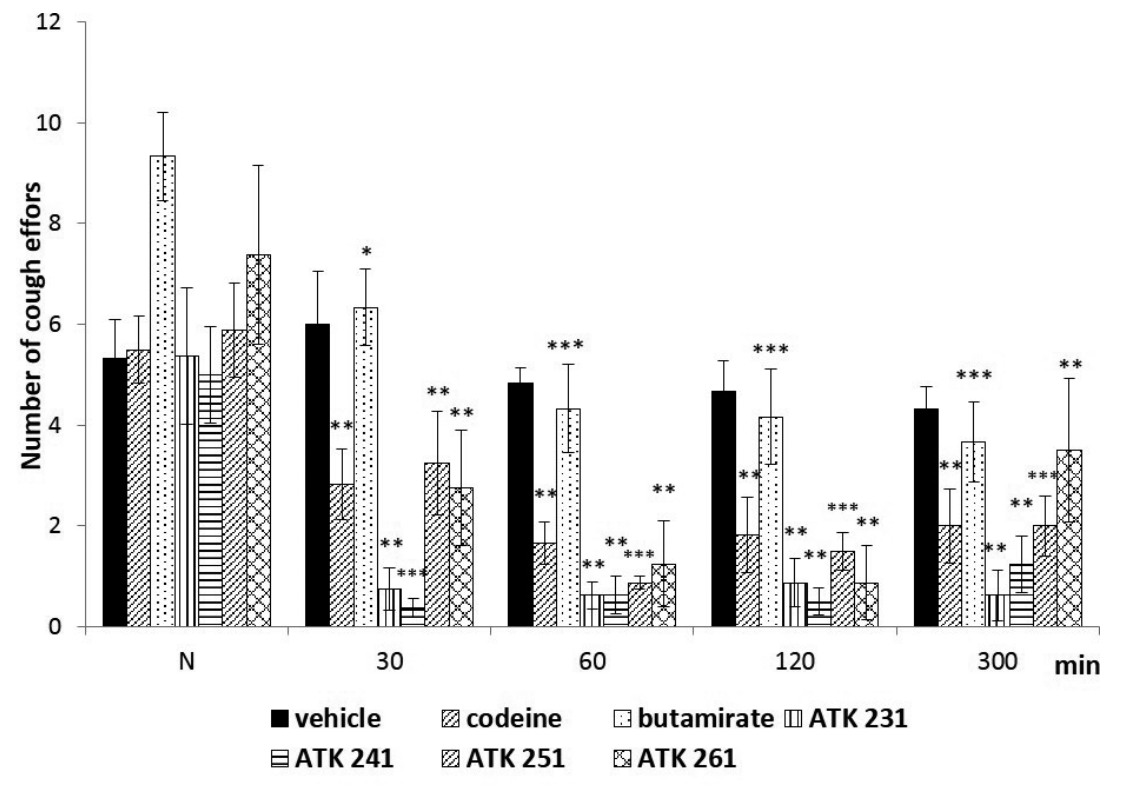

Figure 1. Number of citric acid-induced cough efforts after oral application of ATK 231, ATK 241, ATK 251 and ATK 261 in the doses $50 \mathrm{mg} / \mathrm{kg}$ of body weight compared to vehicle (water for injection, "negative control" - administered orally in the dose $1 \mathrm{ml} / \mathrm{kg}$ of body weight), codeine ("positive control 1" - administered orally in the dose $10 \mathrm{mg} / \mathrm{kg}$ of body weight) and butamirate ("positive control 2" - administered orally in the dose $50 \mathrm{mg} / \mathrm{kg}$ of body weight). Axis $\mathrm{x}$ represents time intervals of the chemical stimulation of the airways and axis y represents the number of cough efforts. $\mathrm{N}$, number of cough efforts recorded before administration of substances. The columns are represented as mean values of number of cough efforts; the range denotes standard error of means \pm SEM. ${ }^{\star} p<0.05,{ }^{* *} p<0.01$, ${ }^{* * *} p<0.001$ in comparison with vehicle. between tested substances. We observed statistically significantly higher total antitussive activity of ATK $231(p=0.007)$ and ATK $241(p=0.021)$. ATK $231(p=0.005)$, ATK 241 $(p=0.016)$ and ATK $251(p=0.027)$ showed significantly higher total antitussive activity comparing to butamirate citrate (Fig. 2).

None of the tested samples (ATK 231, ATK 241, ATK 251 or ATK 261) as well as codeine phosphate and butamirate citrate significantly changed specific airway resistance during the experiment (Fig. 3).

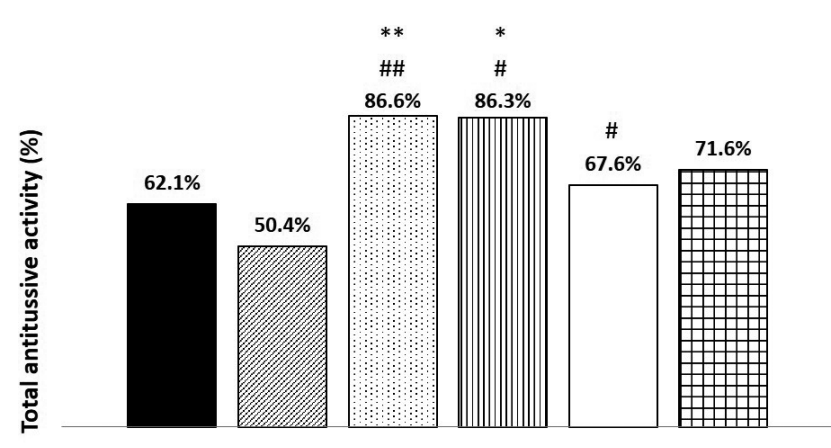

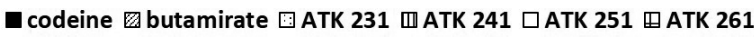

Figure 2. The comparison of the total antitussive activities of ATK 231, ATK 241, ATK 251 and ATK 261 administered in the doses $50 \mathrm{mg} / \mathrm{kg}$ of body weight orally with codeine phosphate administered in the dose $10 \mathrm{mg} / \mathrm{kg}$ of body weight orally and butamirate citrate administered orally in the dose $50 \mathrm{mg} / \mathrm{kg}$ of body weight. ${ }^{*} p<0.05,{ }^{* *} p<0.01$ in comparison with codeine phosphate; ${ }^{\#} p<$ $0.05,{ }^{\# \#} p<0.01$ in comparison with butamirate citrate.
We did not observe any notable side effects after oral administration of ATK 231 and ATK 241. We observed two fatal events during experiment with ATK 251 and 261. First animal died during inhalation of citric acid in the time interval of 30 minutes after administration of ATK 251. Second animal died immediately after inhalation of citric acid 60 min after administration of ATK 261.

\section{Discussion}

We found, that synthetic analogues, esters of alcoxyphenyl carbamic acid marked as ATK 231, ATK 241, ATK 251 and ATK 261, which were structurally related to butamirate citrate or pentoxyverine, after oral administration in the dose $50 \mathrm{mg} / \mathrm{kg}$ of body weight significantly suppressed the number of cough efforts induced chemically by inhalation of citric acid in conscious male guinea pigs. Two compounds, ATK 231 and ATK 241, also showed significantly higher total antitussive activity comparing to codeine phosphate, the oldest and the most used antitussive drug in clinical practice (Chung and Widdicombe 2009). Three of them, ATK 231, ATK 241 and ATK 251, had also significantly higher total antitussive activities as chemically related butamirate citrate, widely used non-narcotic antitussive agent in clinical practice (Jurica 2013).

Oral administrations of ATK 231 and ATK 241 were well tolerated without any notable unwanted effect. We observed fatal adverse events in two animals in groups with ATK 251 and ATK 261 (one animal in each group). Both events occurred during inhalation of citric acid or immediately after it. This indicates rather potential severe 

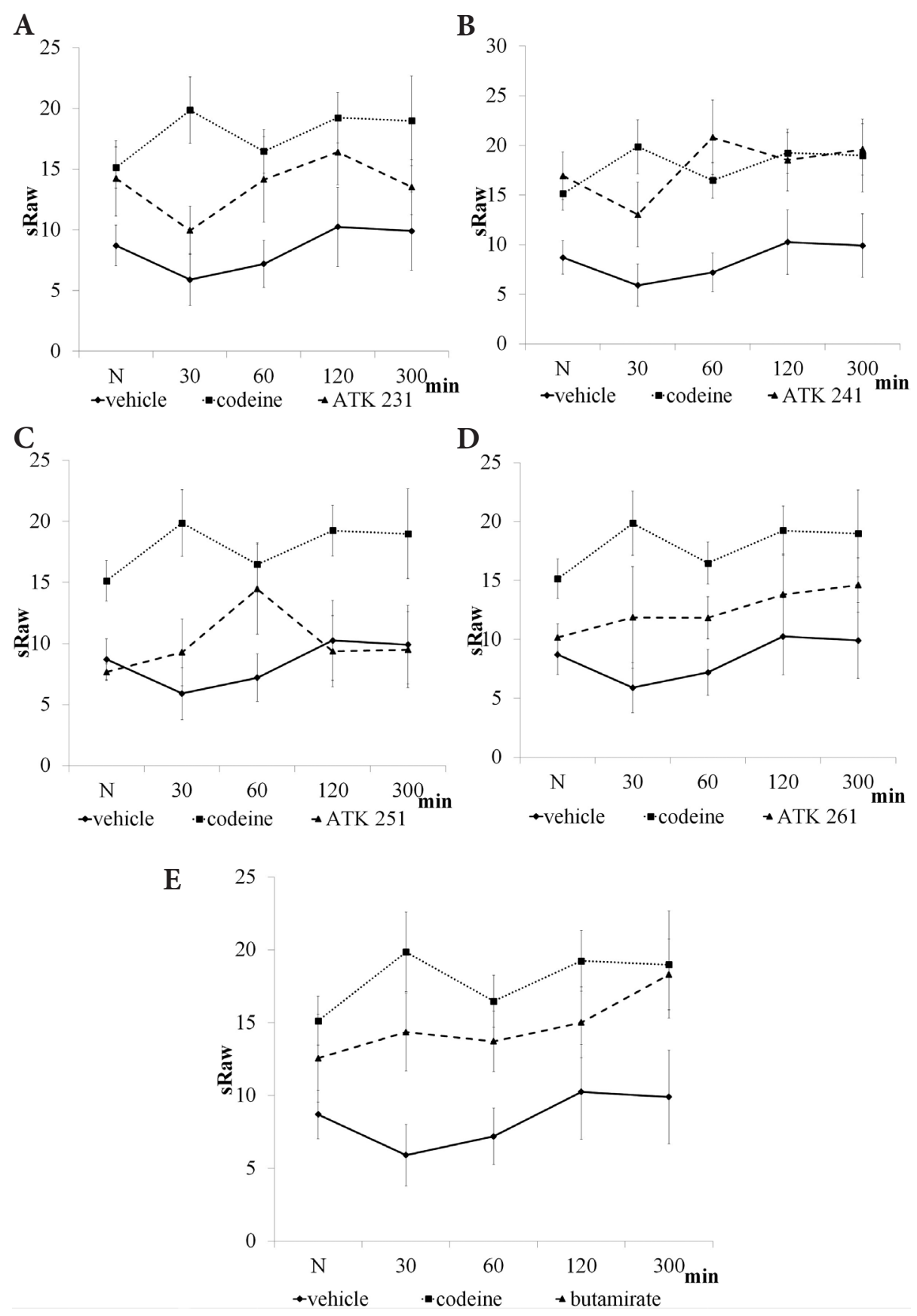

Figure 3. The influence of ATK 231 (A), ATK 241 (B), ATK 251 (C), ATK 261 (D) and butamirate citrate (E) administered orally in the doses $50 \mathrm{mg} / \mathrm{kg}$ of body weight on specific airways resistances (sRaw) in healthy adult conscious guinea pigs, compared to vehicle (water for injection, "negative control" administered orally in the dose 1 $\mathrm{ml} / \mathrm{kg}$ of body weight) and codeine ("positive control 1" - administered orally in the dose $10 \mathrm{mg} / \mathrm{kg}$ of body weight).

acute reaction to inhaled citric acid than possible reaction connected to tested substances. All other animals tolerated both substances without any notable adverse events. The definitive statement that oral administration of ATK 251 and ATK 261 is really not connected with possible toxic effect will require the confirmation with larger group of experimental animals.

The exact mechanism of antitussive activity of tested substances is unknown. However, esters of alkoxyphenyl carbamic acid were described to have the local anesthetic and antibacterial properties (Benes et al. 1972; Cizmarik et al. 1978; Mlynarcik et al. 1991). We assume that these properties would be probably parts of the major mechanisms contributing to the observed antitussive activity. Butamirate citrate has been described previously as moderately acting spasmolytic agent and would thus lead to decrease in specific airway resistance (Korpas and Nosalova 1991). Surprisingly, our results showed no statistically significant alteration in specific 
airways resistance seen after administration of butamirate citrate, neither in ATK 231, ATK 241, ATK 251 or ATK 261. This would suggest that active bronchodilation did not play a major role in antitussive effect seen in our study. Similar findings have been published by the authors Hoskyns et al. (1991), McKenzie et al. (2001) and Shields et al. (2008). They have shown that bronchodilators are not effective for acute therapy of cough in non-asthmatic patients. Braman (2006) also elicited that short acting beta-agonists in stable patients with chronic bronchitis steadily relieved dyspnea but reduce the chronic cough only in some patients. In spite of this fact the studies showing that topical administration of bronchodilators is effective for short term cough suppression have been published (Chong et al. 2005; Freund-Michel et al. 2010; El-Hashim et al. 2011; Sutovska et al. 2012). We assume that cough suppressions described by these authors were related to rather release of pre-existing bronchoconstriction usually accompanying allergic inflammation of the airways. As we used healthy animals with intact airways in our experiments, the administration of substances did not lead to noticeable bronchodilation, which would be detectable by decrease of specific airways resistance. Nevertheless, we have clearly demonstrated that various esters of alcoxyphenyl carbamic acid (ATK 231, 241, 251 and 261) possess very high cough suppressive effect without significant changes of specific airway resistance.

The question remains whether the esters of alcoxyphenyl carbamic acid - ATK 231, ATK 241, ATK 251 and ATK 261, suppress the cough reflex just by the peripheral mechanisms. Is it possible that cough suppressive effect is also mediated via central mechanisms? Chemically similar and thus related butamirate citrate suppresses the cough by influencing peripheral as well as central structures. Some reports showed butamirate as agonist on sigma receptor binding sites for dextromethorphan and some activity of butamirate on NMDA receptors was reported as well (Klein and Musacchio 1989). Based on these observations it is obvious that butamirate would exert both peripheral and central antitussive activities. Tested esters of alcoxyphenyl carbamic acid (ATK 231, ATK 241, ATK 251 and 261) as chemically related to butamirate could thus possess the similar central cough suppressing activity on the level of sigma and NMDA receptors. The differences in antitussive activity among the tested analogues of the alcoxyphenyl carbamic acid could be thus caused and explained by structural differences potentially important for ligand-receptor interaction on this level. This as well as exact mechanism of central antitussive activity remains to be addressed by future specific experiments and analyses. Similarly, relatively high doses of studied compounds $(50 \mathrm{mg} / \mathrm{kg}$ ) were used in experiments. We use the same dosage of all tested antitussive compounds to preserve the uniformity of experiments, which enables the comparison of results from individual experiments. The main aim of this study was to evaluate antitussive activity of the esters of alcoxyphenyl carbamic acid; therefore the determination of optimal or minimal doses to achieve sufficient antitussive effect would be the aim of follow-up experiments.

Impressive cough suppressive activity of esters of alcoxyphenyl carbamic acid seen in our animal experiments provides the promising insight into this new potential antitussive therapeutic option. Good tolerance of these substances observed in our animals as well as absence of significant influence on airways resistance could contribute to its possible therapeutic potential as well.

Acknowledgement. This publication is the result of the project implementation: Biomedical Center Martin ITMS project code: 26220220187 supported by the Operational programme Research and innovation funded by the ERDF.

Conflict of interests. The authors declare no conflicts of interest in relation to this article.

\section{References}

Benes L, Borovansky A, Hartl J, Kopacova L (1972): Local anesthetics. XL. Basic isopropylesters of substituted carbanilic acids. Cesk. Farm. 21, 150-152

Braman SS (2006): Chronic cough due to chronic bronchitis: ACCP evidence-based clinical practice guidelines. Chest 129, 104-115S

https://doi.org/10.1378/chest.129.1_suppl.104S

Brown C, Fezoui M, Selig WM, Schwartz CE, Ellis JL (2004): Antitussive activity of sigma-1 receptor agonists in the guinea-pig. Br. J. Pharmacol. 141, 233-240 https://doi.org/10.1038/sj.bjp.0705605

Calderon SN, Izenwasser S, Heller B, Gutkind JS, Mattson MV, Su TP, Newman AH (1994): Novel 1-phenylcycloalkanecarboxylic acid derivatives are potent and selective sigma 1 ligands. J. Med. Chem. 37, 2285-2291 https://doi.org/10.1021/jm00041a006

Carissimi M, Cattaneo A, D'Ambrosio R, De Pascale V, Grumelli E, Milla E, Ravenna F (1965): Basic ethers of guaiacol and thymol with a polyoxyethylenic chain and their main pharmacological activities. New antitussives. J. Med. Chem. 8, 542-545 https://doi.org/10.1021/jm00328a035

Chong CF, Chen CC, Ma HP, Wu YC, Chen YC, Wang TL (2005): Comparison of lidocaine and bronchodilator inhalation treatments for cough suppression in patients with chronic obstructive pulmonary disease. Emerg. Med. J. 22, 429-432 https://doi.org/10.1136/emj.2004.015719

Chung KF, Widdicombe JG (2009) Cough: setting the scene. Handb. Exp. Pharmacol. 187, 1-21 https://doi.org/10.1007/978-3-540-79842-2_1

Cizmarik J, Mitosinkova M, Borovansky A, Svec P (1978): Local anesthetics. 66. Dimethylaminoethylesters of alkoxyphenyl carbamic acids. Pharmazie 33, 509-512 
Derebery MJ, Dicpinigaitis PV (2013): New horizons: Current and potential future self-treatments for acute upper respiratory tract conditions. Postgrad. Med. 125, 82-96 https://doi.org/10.3810/pgm.2013.01.2605

Dicpinigaitis PV (2011): Cough: an unmet clinical need. Br. J. Pharmacol. 163, 116-124 https://doi.org/10.1111/j.1476-5381.2010.01198.x

Eddy NB, Friebel H, Hahn KJ, Halbach H (1969): Codeine and its alternates for pain and cough relief. 4. Potential alternates for cough relief. Bull World Health Organ. 40, 639-719

El-Hashim AZ, Edafiogho IO, Jaffal SM, Yousif MH, Ezeamuzie CI, Kombian SB (2011): Anti-tussive and bronchodilator mechanisms of action for the enaminone E121. Life Sci. 89, 378-387 https://doi.org/10.1016/j.lfs.2011.07.007

Freund-Michel VC, Birrell MA, Giembycz MA, Hele DJ, Haj-Yahia S, Belvisi MG (2010): Beta(2)-agonists block tussive responses in guinea pigs via an atypical cAMP-dependent pathway. Eur. Respir. J. 35, 647-654 https://doi.org/10.1183/09031936.00034009

Hoskyns EW, Thomson A, Decker E, Hutchins A, Simpson H (1991): Effect of controlled release salbutamol on nocturnal cough in asthma. Arch. Dis. Child. 66, 1209-1212 https://doi.org/10.1136/adc.66.10.1209

Jurica J (2013): Current treatment of cough. Pediatrie pro Praxi 14, 30-38

Klein M, Musacchio JM (1989): High affinity dextromethorphan binding sites in guinea pig brain. Effect of sigma ligands and other agents. J. Pharmacol. Exp. Ther. 251, 207-215

Korpas J, Nosalova G (1991) Pharmacotherapy of Cough. Osveta, Martin

McKenzie SA, Mylonopoulou M, Bridge PD (2001): Bronchodilator responsiveness and atopy in 5-10-yr-old coughers. Eur. Respir. J. 18, 977-981 https://doi.org/10.1183/09031936.01.00071901

Miko P (2005): The use and safety of butamirate containing drops, syrup and depot tablets in Hungary. Orv. Hetil. 146, 609-612
Mlynarcik D, Bittererova J, Cizmarik J, Masarova L (1991): The effect of piperidinoethylesters of n-alkoxyphenyl-carbamic acids on bacterial cells]. Cesk. Farm. 40, 25-28

Molassiotis A, Bailey C, Caress A, Brunton L, Smith J (2010): Interventions for cough in cancer. Cochrane Database Syst. Rev. CD007881 https://doi.org/10.1002/14651858.CD007881.pub2

Nosal'ova G, Strapkova A (1986): Changes in the cough reflex after the administration of guaifenesin. Bratisl. Lek. Listy 85, 451-457

Pennock BE, Cox CP, Rogers RM, Cain WA, Wells JH (1979): A noninvasive technique for measurement of changes in specific airway resistance. J. Appl. Physiol. 46, 399-406 https://doi.org/10.1152/jappl.1979.46.2.399

Schenker H (1983): Efficacy of morclofon, an new synthetic antitussive agent, in geriatric patients. Results of a double-blind study. Ther. Umsch. 40, 358-361

Shields MD, Bush A, Everard ML, McKenzie S, Primhak R (2008): British Thoracic Society Cough Guideline, G. BTS guidelines: Recommendations for the assessment and management of cough in children. Thorax. 63 Suppl 3, iiil-15

Sutovska M, Capek P, Franova S, Pawlaczyk I, Gancarz R (2012): Antitussive and bronchodilatory effects of Lythrum salicaria polysaccharide-polyphenolic conjugate. Int. J. Biol. Macromol. 51, 794-799 https://doi.org/10.1016/j.ijbiomac.2012.07.015

Szuk B, Kalo I, Winkler I, Mihoczy L (1987): Clinical studies with butamirate citrate in bronchial asthma and following acetylcholine induction. Prax Klin. Pneumol. 41, 971-973

Young EC, Smith JA (2011): Pharmacologic therapy for cough. Curr. Opin. Pharmacol. 11, 224-230

https://doi.org/10.1016/j.coph.2011.06.003

Received: May 26, 2017

Final version accepted: October 5, 2017 